\title{
BMJ Open What is the impact of giant cell arteritis on patients' lives? A UK qualitative study
}

\author{
Jennifer Liddle, ${ }^{1,2}$ Roisin Bartlam, ${ }^{1}$ Christian D Mallen, ${ }^{1}$ Sarah L Mackie, ${ }^{3}$ \\ James A Prior, ${ }^{1}$ Toby Helliwell, ${ }^{1}$ Jane C Richardson ${ }^{1}$
}

To cite: Liddle J, Bartlam R, Mallen $\mathrm{CD}$, et al. What is the impact of giant cell arteritis on patients' lives? A UK qualitative study. BMJ Open 2017;7:e017073. doi:10.1136/ bmjopen-2017-017073

- Prepublication history for this paper is available online To view these files, please visit the journal online (http://dx.doi. org/10.1136/bmjopen-2017017073).

Received 30 March 2017 Revised 2 June 2017 Accepted 16 June 2017

\section{CrossMark}

${ }^{1}$ Research Institute for Primary Care and Health Sciences, Keele University, Keele, UK

${ }^{2}$ Institute of Health and Society, Newcastle University, Newcastle upon Tyne, UK

${ }^{3}$ Leeds Institute of Rheumatic and Musculoskeletal Medicine, University of Leeds, Leeds, UK

Correspondence to

Dr Jennifer Liddle;

jennifer.liddle@newcastle.ac.uk

\section{ABSTRACT}

Objectives Clinical management of giant cell arteritis (GCA) involves balancing the risks and burdens arising from the disease with those arising from treatment, but there is little research on the nature of those burdens. We aimed to explore the impact of giant cell arteritis (GCA) and its treatment on patients' lives.

Methods UK patients with GCA participated in semistructured telephone interviews. Inductive thematic analysis was employed.

Results 24 participants were recruited (age: 65-92 years, time since diagnosis: 2 months to $>6$ years). The overarching themes from analysis were: ongoing symptoms of the disease and its treatment; and 'lifechanging' impacts. The overall impact of GCA on patients' lives arose from a changing combination of symptoms, side effects, adaptations to everyday life and impacts on sense of normality. Important factors contributing to loss of normality were glucocorticoid-related treatment burdens and fear about possible future loss of vision.

Conclusions The impact of GCA in patients' everyday lives can be substantial, multifaceted and ongoing despite apparent control of disease activity. The findings of this study will help doctors better understand patient priorities, legitimise patients' experiences of GCA and work with patients to set realistic treatment goals and plan adaptations to their everyday lives.

\section{INTRODUCTION}

Giant cell arteritis (GCA) is the the most common form of primary systemic vasculitis and primarily affects older people. ${ }^{12}$ The vasculitic process may result in ischaemic manifestations such as anterior ischaemic optic neuropathy or jaw claudication, which may produce groups of characteristic symptoms leading to clinical diagnosis. Presentation may, however, be non-specific with systemic features such as fever and weight loss and in this case diagnosis is facilitated by laboratory, histological and imaging tests.

The mainstay of treatment remains highdose glucocorticoids (initially $40-60 \mathrm{mg}$ of prednisone equivalent), aiming to control disease activity. The dose is subsequently tapered gradually over several years but

\section{Strengths and limitations of this study}

- This study provides the first qualitative analysis of the impact of GCA and its treatment on patients' everyday lives.

- Two approaches to sampling were adopted in recognition that patients associated with the charity PMRGCAuk were unlikely to be representative of all GCA patients, and we also acknowledge that patients who felt that GCA had a large impact on their lives may have been more likely to volunteer to participate.

- Interviews were conducted with a sample of people from different social backgrounds and age groups; future research might actively aim to recruit people from a range of ethnic and cultural groups.

- The data presented are based on patients' retrospective accounts of their experiences, which may change with time.

- Our methods did not allow us to verify the clinical diagnosis of GCA from participants' medical records or the results of medical tests they had undergone, but the fact that all participants were able to describe their glucocorticoid treatment provided reassurance that our sampling strategy identified individuals from the population of interest.

is increased in the face of relapse. Glucocorticoid-related adverse effects result in considerable morbidity in this patient population. ${ }^{3}$ Thus, clinical management of GCA involves a balance between the risks and burdens of the disease, and the risks and burdens of the treatment. Much has been written about this from the medical perspective; the sparse literature about patient priorities in GCA suggests that patient priorities for GCA include vision, control of arms and legs and personal care abilities. ${ }^{4}$ Qualitative research to develop patient-relevant outcome measures in largevessel vasculitis has been conducted with patients with Takayasu arteritis, a rarer form of large-vessel vasculitis that affects younger adults, ${ }^{5}$ but the experience of older patients 
with GCA remains relatively unexplored. According to Borg and Davidson, 'when it comes to understanding recovery, the trivialities of everyday life must be seen as anything but trivial'. ${ }^{6}$ In order to understand how best to help patients recover from their illness, we aimed to examine GCA and its treatment from the patient perspective, through the lens of its impact on patients' everyday lives.

\section{METHODS \\ Design}

This was a qualitative study using semi-structured telephone interviews and inductive thematic analysis of data. The study received ethical approval from Keele University's Research Ethics Committee (Ref. ERP2254) and verbal and written consent was obtained from all participants (a completed paper consent form was posted back to the research team by the participant after each interview).

\section{Participants and data collection}

Participants were recruited using two approaches. First, letters were sent to patients with GCA who had taken part in a cross-sectional survey, recruited through general practice medical records, and who had consented to further contact. Second, an email was circulated by the UK charity PMRGCAuk to its regional groups and members, inviting patients to contact the research team for further information. Only patients who reported that a clinician had diagnosed GCA were included. Purposive sampling categories included age, gender and time since diagnosis. JL and CDM developed a list of topics and prompts to guide interview discussions.

Following informed consent, RB conducted and audio-recorded semi-structured telephone interviews with recruited patients with GCA until the point where the research team agreed there were 'diminishing returns' from further data collection and that data saturation was sufficient. ${ }^{7-9}$ Brief fieldnotes were written after each interview to record thoughts about emerging analytic themes and data coding.

\section{Analysis}

All interview recordings were transcribed and pseudonyms used to preserve participant confidentiality. An inductive thematic approach was taken to analysis. ${ }^{10} \mathrm{RB}$ completed an initial categorising and line-by-line coding of all data from the transcripts using QSR NVivo V.10 and discussed the development of codes and themes with JL. JL then continued with additional analysis (in discussion with JR and CDM), developing codes and themes focusing specifically on the impact of symptoms and treatment on patients' everyday lives. After further discussion, JL and JR developed a visual representation of these themes (figure 1).

\section{RESULTS}

Participants' ages ranged from 65 to 92 years and time since diagnosis ranged from 2 months to over 6 years. All participants were White British (table 1). Interviews lasted between 29 and $128 \mathrm{~min}$. One transcript was excluded from analysis because the patient contacted the research team to say that her diagnosis of GCA had been changed to a diagnosis of lymphoma.

Patients did not conceptualise the impact of GCA as a set of discrete symptoms or side effects, but as an ongoing experience, changing over time, resulting from the combination and co-occurrence of multiple factors. Figure 1 is a visual representation of subthemes and codes within the data, demonstrating the psychological impacts, symptoms and side effects that patients experienced, and the aspects of their everyday lives requiring adaptation as a result. Patients were often unable to distinguish between disease-related symptoms and treatment-related side effects and did not make a distinction in terms of impact; the impact and combination of the experiences was most important to patients, regardless of the cause. Presentation of findings reflects this.

Two overarching themes from the qualitative data are presented: ongoing symptoms of the disease and its treatment and 'life-changing' impacts.

Theme 1: ongoing symptoms of the disease and its treatment Patients gave detailed accounts of the symptoms of their disease and its treatment that impacted on their everyday lives, ranging from extreme to minimal. The data in tables 2 and 3 illustrate the extent to which the experience of GCA and its treatment varied between patients, in both type and duration.

\section{Types of symptoms}

"The effects it had on me, my body and my mind as well..."

Fatigue, pain, sight loss, other visual symptoms, changes in mood and changes in physical appearance and sleep (table 2) were particularly reported as having implications for the extent to which patients could continue living their lives in the same way as they had done before the onset of GCA. The experience of permanent visual loss was associated with feelings of bereavement and vulnerability. Other generalised, persistent symptoms such as dizziness and loss of strength were also reported by patients.

\section{Duration of impact}

"He says, 'I'm going to give you a course of treatment', he says, 'which is gonna last for some time_-more like years than weeks', he says, "but it will control it and hopefully we can stop it'."

The experiences of patients varied widely, with some reporting that the impact of GCA and/or its treatment on their everyday lives had continued for many years after diagnosis (up to 5 years, and longer for those who developed new features such as sight loss), while others reported that the impact of GCA and/or its treatment on their lives had been relatively short-lived. 


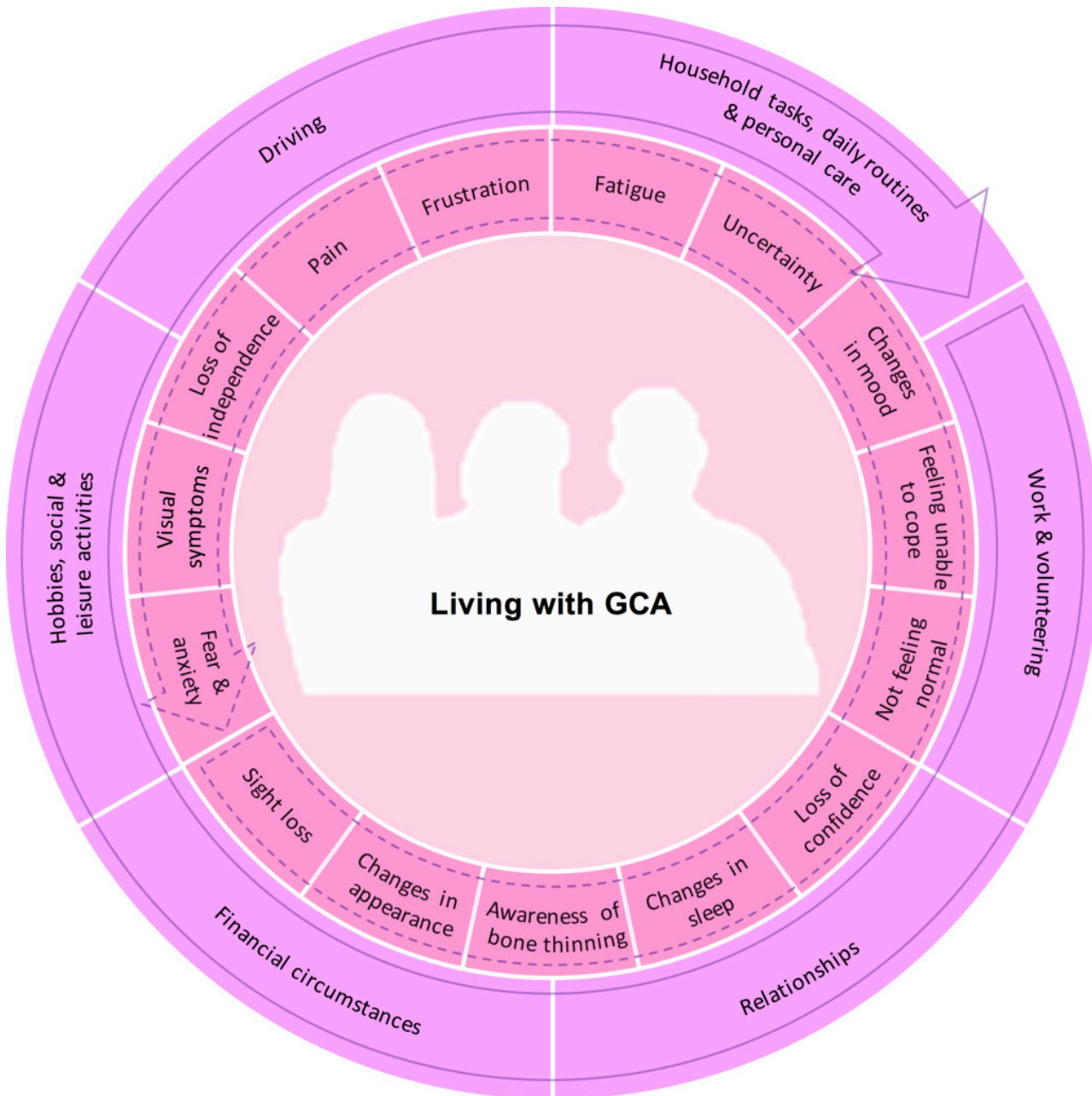

Figure 1 This diagram represents the multiple physical and psychological symptoms experienced by patients living with a diagnosis of giant cell arteritis (GCA) (inner circle), and the multiple domains of daily living (outer circle) that these symptoms can impact on. The arrows denote the rotation of each circle, with the intention of visually representing the ability of individual/ groups of symptoms to impact on multiple domains of daily living. The rotation also indicates the potential for the relative importance and impact of each factor to vary over time due to fluctuations in the underlying disease, the dose and duration of glucocorticoid treatment, the influence of comorbidities and changes in individual adaptations and approaches to selfmanagement.

The impact of symptoms could be categorised as: a) minimal or no long-term impact; b) continuing symptoms over time periods ranging from weeks to years or c) changes in health as a result of permanent visual loss and/or new health problems that now required management (table 3). There were no particular differences between the impacts or types of symptoms that were experienced minimally and those that became long-term.

Some patients had both long-term and permanent impacts. While some of those who experienced long-term impacts and symptoms reported that these resolved or diminished in the months and years following the initiation of treatment, others had not yet perceived such improvements. In particular, the continuation of non-specific symptoms (table 2) caused confusion and frustration for patients, especially in the context of being told that their inflammatory marker test results were within the normal range.
Theme 2: 'life-changing' impacts

Patients whose symptoms had resolved quickly did not feel that GCA had changed their lives. However, the ongoing impacts of GCA symptoms and treatment side effects were described as being 'life changing' (Cressida, 62, 5 years 5 months since diagnosis) and 'restricting my life totally' (Dorothy, 78, 2 years 11 months since diagnosis).

Activities, behaviours and circumstances

"I just used the energy on what I absolutely had to do and everything else was on hold"

Those patients with ongoing symptoms of GCA and its treatment generally described how these had substantially affected their everyday lives including aspects of life such as: work and voluntary roles; relationships; hobbies, social and leisure activities; household tasks, daily routines and personal care; financial circumstances and driving (table 4). 
Impacts could be direct (eg, as a result of fatigue or visual loss making activities unmanageable) or indirect (such as the fluctuating nature and unpredictability of symptoms affecting an individual's ability to plan or commit to future activities or events). Both types of impact required patients to adapt, consequently losing or reducing the sense of normality in their everyday lives. Patients also reflected on the feelings of guilt and regret that they had when their relationships with other people were affected.

\section{Thoughts and feelings}

"To be able to live a normal life, I suppose, is the thing that is desirable"

Frustration arose as a result of patients being unable to continue with activities and tasks in the same way as they had before the onset of GCA (table 5). Patients talked about how these unwanted adaptations to their everyday lives affected the extent to which they felt independent, and the need to rely on others or ask for help was particularly unwelcome. Such reductions in independence or being unable to continue with everyday life as normal resulted in some patients feeling that they were not coping or managing the situation as well as they believed they should be able to. Their accounts demonstrated tendencies towards self-criticism rather than self-compassion, particularly when a less active, less mentally positive or less independent role was not congruent with their established perceptions of themselves and their identity.

Other psychological impacts were also prominent in patients' accounts of living with GCA. These included symptoms of low mood or depression mentioned earlier (see table 2), but reduced confidence, fear and uncertainty were also common themes in patients' accounts (table 5). Visible bodily changes resulting from glucocorticoid treatment and visual loss were two specific causes of feelings of reduced confidence and/or low mood, again impacting on perceptions of self and identity. While the actual experience of symptoms like permanent visual loss was frightening, being afraid of what might happen (ie, losing vision, experiencing a relapse of symptoms and of the potential future side effects of treatment) was a strong theme in the data. This was not exclusive to patients who had experienced ongoing or permanent symptoms.

For those who did express fears about the future, these fears were compounded by the uncertainty that patients felt about the likelihood of events such as visual loss occurring, along with their other unanswered questions about whether their symptoms would improve and which of their symptoms were due to GCA and/or its treatment or other conditions. Reassurance from clinicians sometimes helped to reduce anxiety (table 5). However, the lack of a clear-cut or predictable relationship between the length of time since the onset of symptoms and the impact of GCA and its treatment on patients' lives (table 3) was a strong feature in the data.

\section{DISCUSSION}

GCA and its treatment present ongoing physical and psychological problems for patients, affecting their everyday lives in a wide variety of ways. As in a recent study of patients with polymyalgia rheumatica, another inflammatory condition of older people that is primarily treated with glucocorticoids, patients in our study described their experience in terms of collective impacts, rather than focusing on localised symptoms. ${ }^{11}$ Practical, social and psychological support may be valuable therapeutic interventions to help patients recover or maintain a sense of normality in everyday life tasks, skills and activities. Patients will likely view recovery as linked with undertaking activities of value and 're-assess

\begin{tabular}{|c|c|c|c|}
\hline & $\begin{array}{l}\text { Male } \\
(\%) n=9\end{array}$ & $\begin{array}{l}\begin{array}{l}\text { Female } \\
(\%) n=15\end{array} \\
\end{array}$ & $\begin{array}{l}\begin{array}{l}\text { Total } \\
(\%) n=24\end{array} \\
\end{array}$ \\
\hline \multicolumn{4}{|c|}{$\begin{array}{l}\text { Age group at interview } \\
\text { (years) }\end{array}$} \\
\hline 60-69 & $1(11)$ & $4(27)$ & $5(21)$ \\
\hline $70-79$ & $7(78)$ & $9(60)$ & $16(67)$ \\
\hline 80-89 & - & 2 (13) & $2(8)$ \\
\hline $90-99$ & 1 (11) & - & $1(4)$ \\
\hline
\end{tabular}

Time since diagnosis (months)

\begin{tabular}{|c|c|c|c|}
\hline$\leq 12$ & - & $4(27)$ & $4(17)$ \\
\hline $13-24$ & $3(33)$ & $3(20)$ & $6(25)$ \\
\hline $25-36$ & $4(44)$ & $3(20)$ & 7 (29) \\
\hline $37-48$ & $1(11)$ & $1(7)$ & $2(8)$ \\
\hline $49-60$ & - & $2(13)$ & $2(8)$ \\
\hline$\geq 61$ & $1(11)$ & $2(13)$ & $3(13)$ \\
\hline \multicolumn{4}{|l|}{ Ethnicity/nationality } \\
\hline White British & $9(100)$ & $15(100)$ & $24(100)$ \\
\hline \multicolumn{4}{|l|}{ Living arrangements } \\
\hline Alone & - & $5(33)$ & $5(21)$ \\
\hline With one other person & $9(100)$ & $10(67)$ & $19(79)$ \\
\hline \multicolumn{4}{|l|}{ Marital status } \\
\hline Married/long-term partner & $9(100)$ & $10(67)$ & $19(79)$ \\
\hline Single & - & $2(13)$ & $2(8)$ \\
\hline Divorced/separated & - & $1(7)$ & $1(4)$ \\
\hline Widowed & - & $2(13)$ & $2(8)$ \\
\hline \multicolumn{4}{|l|}{ Current work status } \\
\hline Retired & $9(100)$ & $12(80)$ & $21(88)$ \\
\hline Part-time work & - & $2(13)$ & $2(8)$ \\
\hline $\begin{array}{l}\text { Not working for health } \\
\text { reasons }\end{array}$ & - & $1(7)$ & $1(4)$ \\
\hline \multicolumn{4}{|l|}{ Recruitment source } \\
\hline Survey & $8(89)$ & $5(33)$ & $13(54)$ \\
\hline PMRGCAuk charity & $1(11)$ & $10(67)$ & $11(46)$ \\
\hline
\end{tabular}




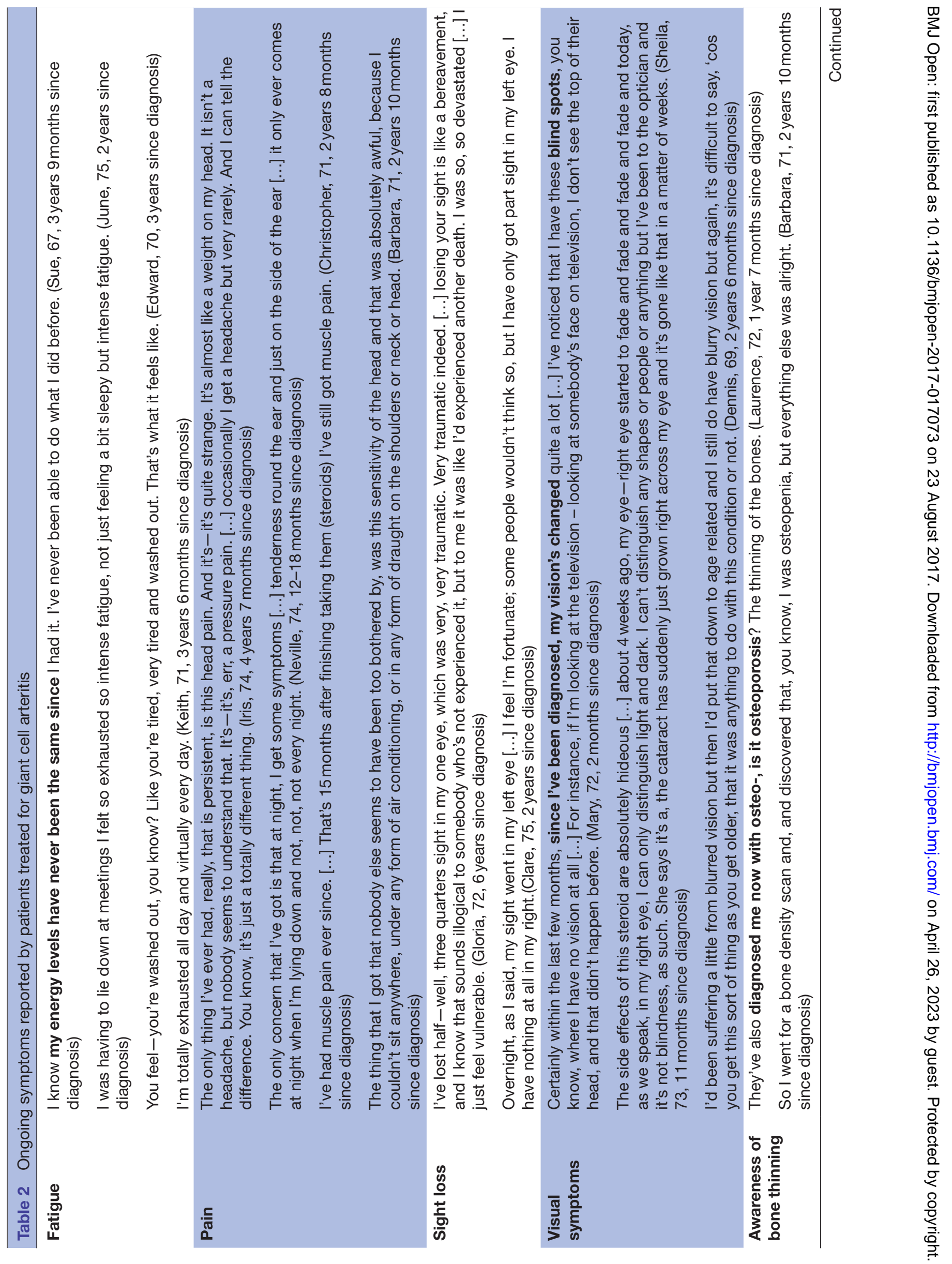




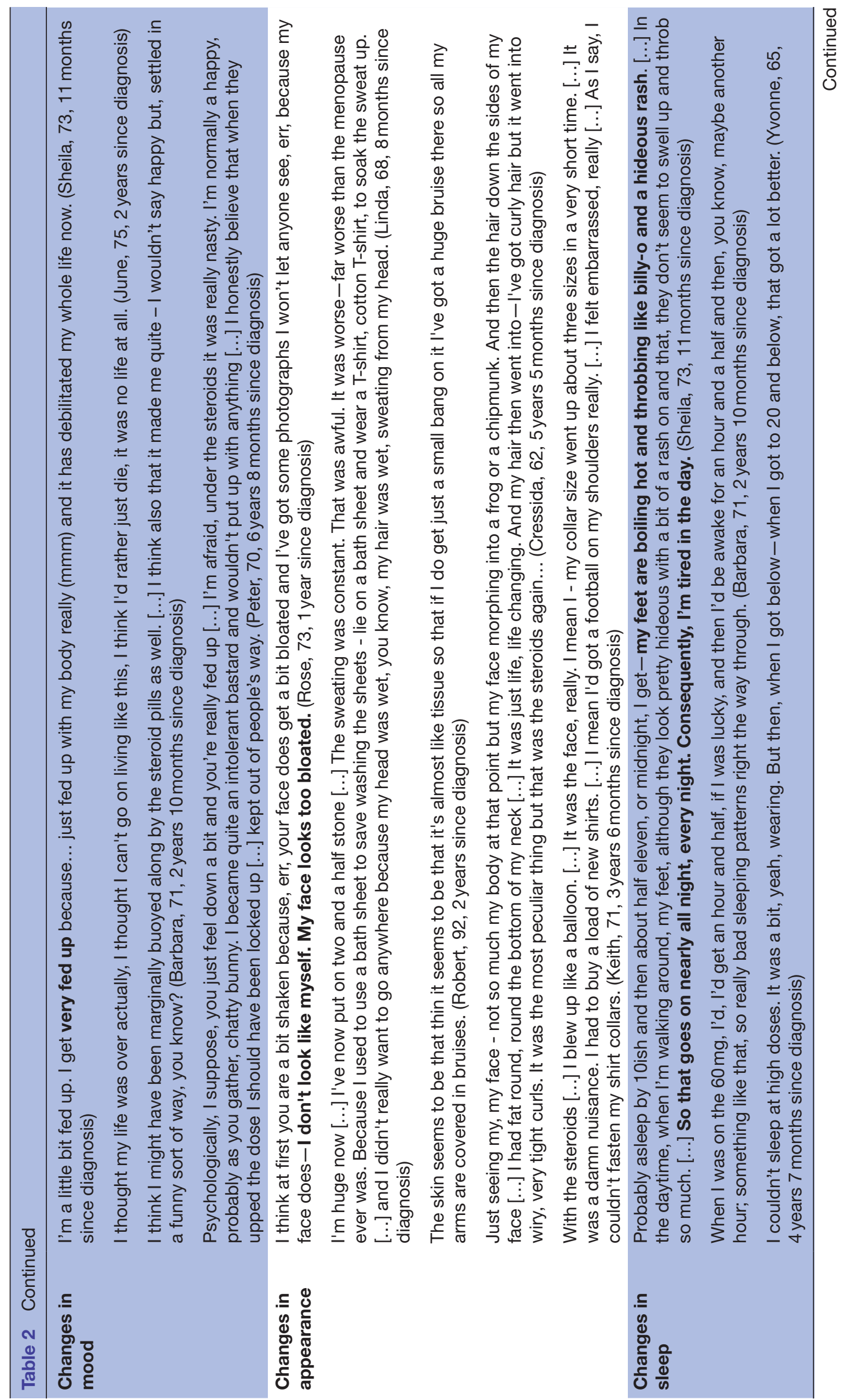


continually and monitor their current well-being', comparing this with their perceptions of normality before diagnosis. $^{12} 13$

Besides the expected impact of permanent visual loss on patients' lives, ${ }^{14}$ it is important to note the extent to which other symptoms including fatigue, pain and 'not feeling normal' continued to affect multiple aspects of the lives of patients with GCA many years after their diagnosis. In addition, psychological consequences such as reduced confidence, anxiety and feelings of reduced independence could extend beyond the duration of the physical symptoms. Thus, the status of a patient in terms of coping, recovery and/or sense of normality in everyday life is somewhat unpredictable and does not necessarily correspond with the length of time since diagnosis/completion of treatment or clinical severity.

Ongoing adaptations were made by patients both as a direct consequence of their symptoms and as a strategy for self-management. Hall et al describe these strategies as part of 'the fight to maintain normality'. ${ }^{12}$ An increased sense of independence may arise from being able to plan changes in advance. Furthermore, 'maintaining the appearance of normality ${ }^{12}$ can be challenging when glucocorticoid treatments cause visible bodily changes, impacting on self-image, mood and confidence, with resulting effects on activities and behaviours.

Finding the optimal balance of information provision is challenging, and by educating patients about the risks of visual loss with GCA, an additional psychological burden is introduced. GCA presents considerable risks in terms of visual loss if left untreated, ${ }^{1516}$ consequently clinicians may emphasise these risks to maximise patient adherence to glucocorticoid treatment. Yet fears about the possibility of visual loss can be very distressing for patients, continuing long after diagnosis. In our study, patients who had lost vision were also concerned about relapse causing further visual loss in the future. In addition, changes in vision from other conditions such as cataract and glaucoma, usually attributed to glucocorticoid therapy, heightened patients' existing anxieties about experiencing permanent visual loss as a result of GCA.

This study provides the first qualitative analysis of the impact of GCA and its treatment on patients' everyday lives. Interviews were conducted with a sample of people from different social backgrounds and age groups. The findings are compatible with existing models of health experiences and research from other chronic conditions. The data presented are based on patients' retrospective accounts of their experiences, which may change with time.

It was not the intention of this study to specifically explore ethnic or cultural factors that may impact on experiences of GCA, but future research might actively aim to recruit people from a range of ethnic groups. In addition, the impact of GCA for people of different ages and/or before and after transition points in the lifecourse such as retirement, and of patients who undergo treatment with evolving biologic regimens, could be 
Table 3 Impact duration of symptoms experienced by patients with treated giant cell arteritis

\section{Minimal or no long- They put me straight on to steroids. [...] everything disappeared after that. And l've had no term impact symptoms since. (Joan, 81, 1 year 4 months since diagnosis)}

As far as living with it goes, um to be quite honest I haven't found any real change um it's not affecting me as far as my day to day living what I do and things all the way through. I think I've been very, very lucky. (David, 71, 2 years 5 months since diagnosis)

\begin{tabular}{|c|c|}
\hline \multirow[t]{3}{*}{$\begin{array}{l}\text { Continuing } \\
\text { symptoms }\end{array}$} & $\begin{array}{l}\text { I'm past my year's date of my first pain in my head and I'm not better. I'm worse than I was at the } \\
\text { start...and really, just the tiredness, legs pain that l've told you [...] I count these cataracts as the bane } \\
\text { of my life. (Sheila, } 73,11 \text { months since diagnosis) }\end{array}$ \\
\hline & $\begin{array}{l}\text { I'm pleased, you know, that I've, that I've got through it all. But that was } 2010 \text {. We're now } 2015 \text {. So it's } \\
\text { only in the last, say, year that I've really got my body strong again [...] it took a good few years after to } \\
\text { really get back my strength. (Cressida, } 62,5 \text { years } 5 \text { months since diagnosis) }\end{array}$ \\
\hline & $\begin{array}{l}\text { [I] can't do the things that I want to now [...] because of the discomfort in my joints, in my arms and } \\
\text { even in the chest. It's really, really uncomfortable [...] I believe it's the reactions from the Prednisolone } \\
\text { because I, I don't, I don't think it's from the Giant Cell Arteritis [...] that seems - after about } 2 \text { month, the, } \\
\text { the headaches went away, although I've still got the inflammation in my bloodstream like, according to } \\
\text { (the rheumatologist), you know but... yeah it's, it's the after effects of, of those-of Pred-, Prednisolone } \\
\text { steroids that I think is causing - this is what's caused my glaucoma problems as well. (Dennis, } 69 \text {, } \\
2 \text { years } 6 \text { months since diagnosis) }\end{array}$ \\
\hline \multirow[t]{2}{*}{ Changes in health } & $\begin{array}{l}\text { You've lived your life with full vision [...] It's really hard. [...] because three quarters of the sight has } \\
\text { gone in my right eye. (Gloria, } 72,6 \text { years since diagnosis) }\end{array}$ \\
\hline & $\begin{array}{l}\text { I've got tablets now... I'm going to have to have long term - you see, I, I, I don't know }- \text { I'm thinking } \\
\text { I'm going to have to have long term things to, to look after this osteoporosis now. (Laurence, 72, } 1 \text { year } \\
7 \text { months since diagnosis) }\end{array}$ \\
\hline
\end{tabular}

explored in the future. The relationship between clinical presentation and/or comorbidities at diagnosis and the subsequent impact on life could also usefully be explored in more detail through a mixed-methods study, particularly given the clinical heterogeneity of GCA at diagnosis and the potential mediating factors such as treatment timing and approach, and individual patient behaviours and psychological responses. This could facilitate identification in advance of patients at higher risk of impacts such as anxiety and loss of normality, who might benefit most from potential support or educational interventions.

Two approaches to sampling were adopted in recognition that those GCA patients who were associated with the charity PMRGCAuk were unlikely to be representative of all patients with GCA. The sample included patients who described minimal impacts, although we acknowledge that those patients who felt that GCA had a large impact on their lives may have been more likely to volunteer to take part in the study. In our view, this does not diminish the importance of our findings about the experiences of patients who do experience ongoing impacts, despite the fact that the prevalence of these experiences has not yet been established in larger populations.

Purposive sampling is not intended to be numerically representative, but instead allows in-depth exploration and insight into experiences of patients. Consequently, the use of relative frequencies is avoided in the text to avoid confusion. Finally, our methodology did not allow us to verify the clinical diagnosis of GCA from participants' medical records or the results of medical tests they had undergone; however, the fact that all participants were able to describe their glucocorticoid treatment provided reassurance that our sampling strategy identified individuals from the population of interest.

\section{CONCLUSIONS}

This study demonstrates that GCA presents patients with considerable ongoing physical and psychological symptoms that affect their everyday lives in a wide variety of ways. These experiences vary over time according to the combination of multiple factors including symptoms, side effects, new health conditions and adaptations and impacts on normality in everyday life. Visible body changes attributed to glucocorticoid therapy and fear of future visual loss were important contributors to the loss of normality reported by patients.

This new understanding of the impact of GCA on patients' lives has important implications for measurement/capture of truly patient-relevant outcomes, both in clinical trials and clinical practice. It also suggests that many patients with GCA would benefit from additional psychological support, whether from peers or professionals.

Clinical management of GCA often focuses on medical concepts such as disease activity, relapse, remission and the prescribing of further medications to mitigate against the consequences of glucocorticoid toxicity. ${ }^{2}$ We suggest that an understanding and acknowledgement of the very different ways patients experience GCA and its treatment will help clinicians negotiate patient-centred treatment plans, including planning adaptations to their lives to 


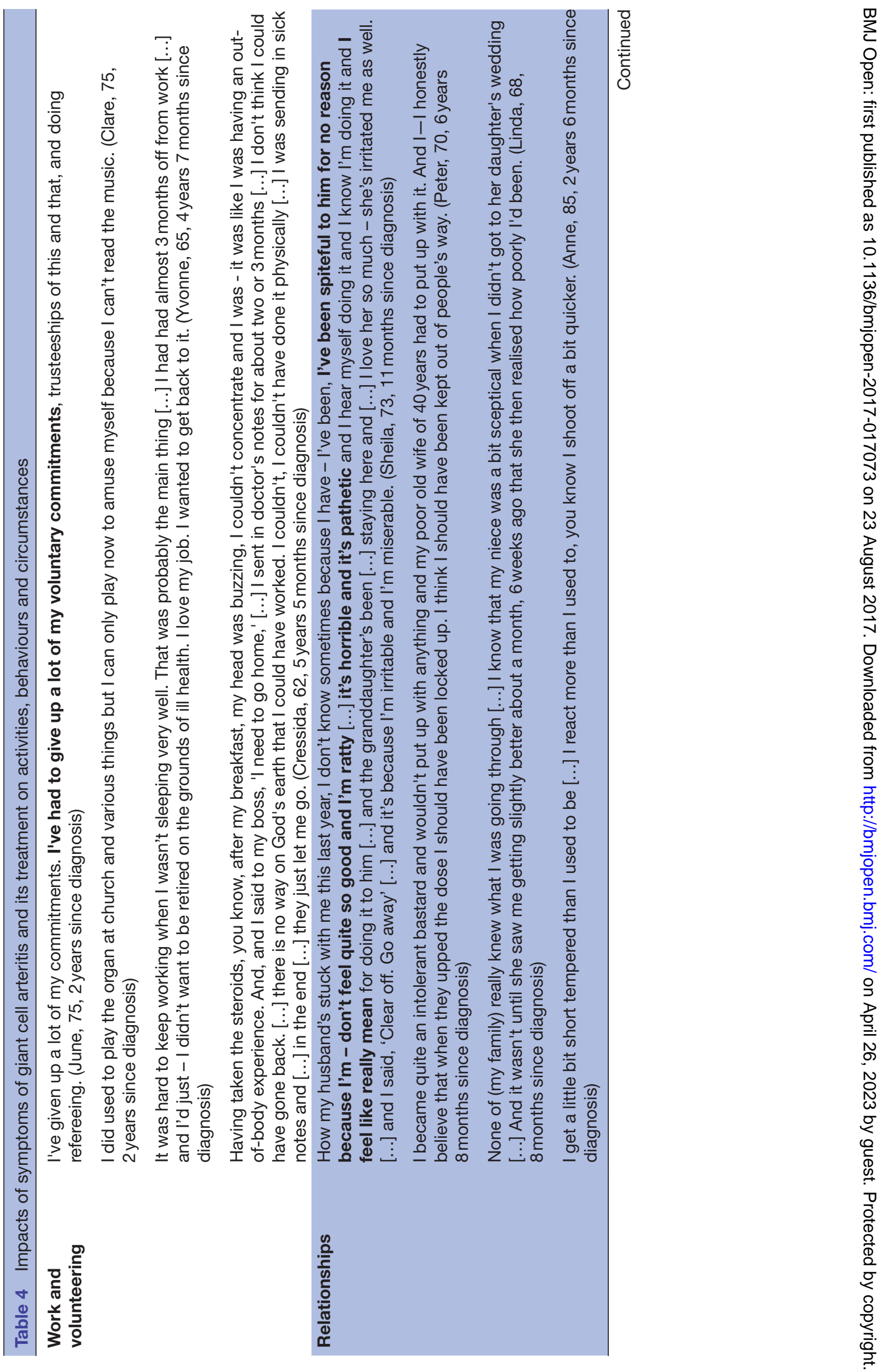




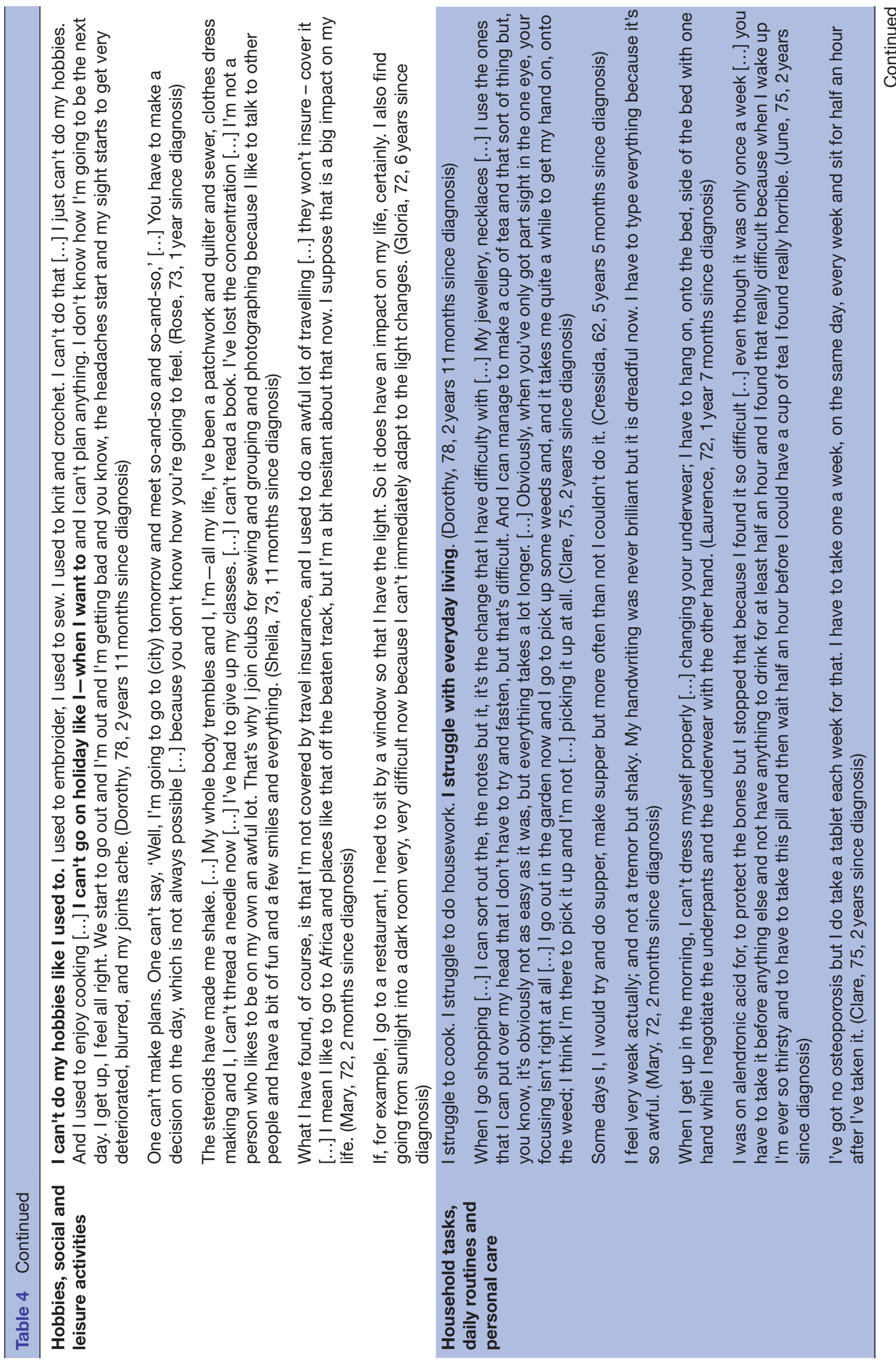




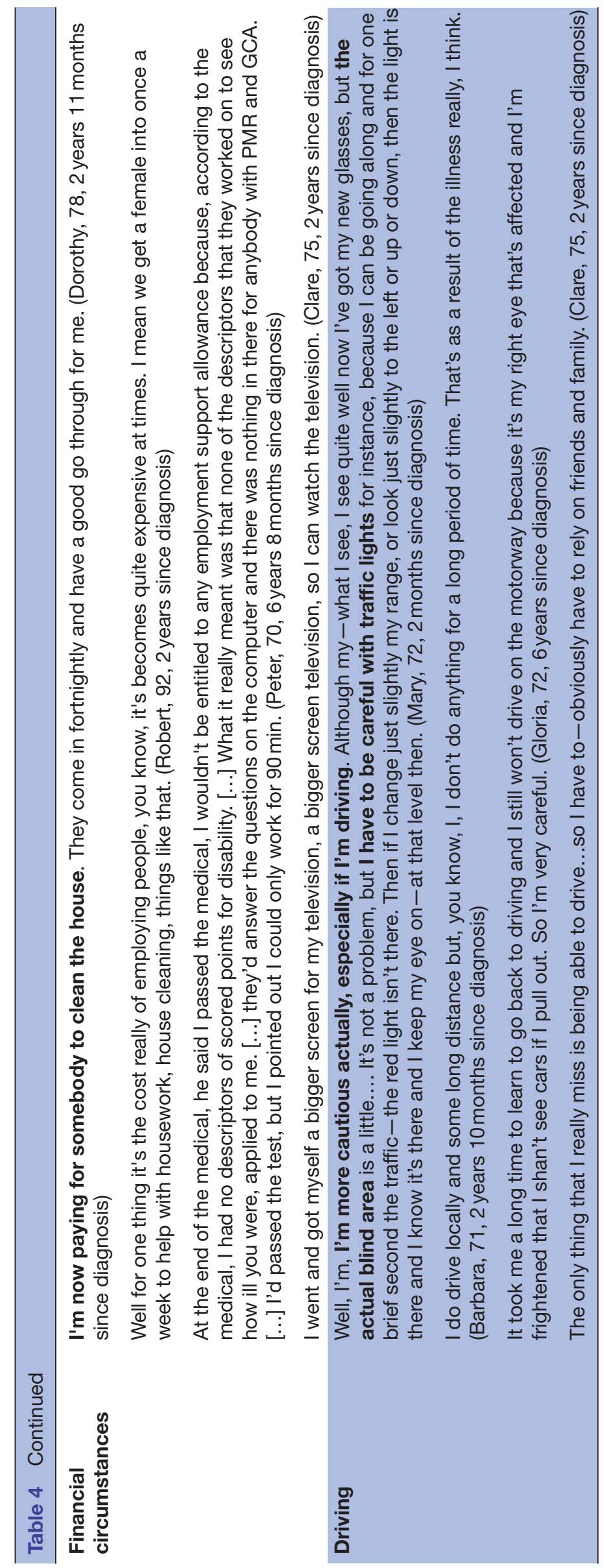




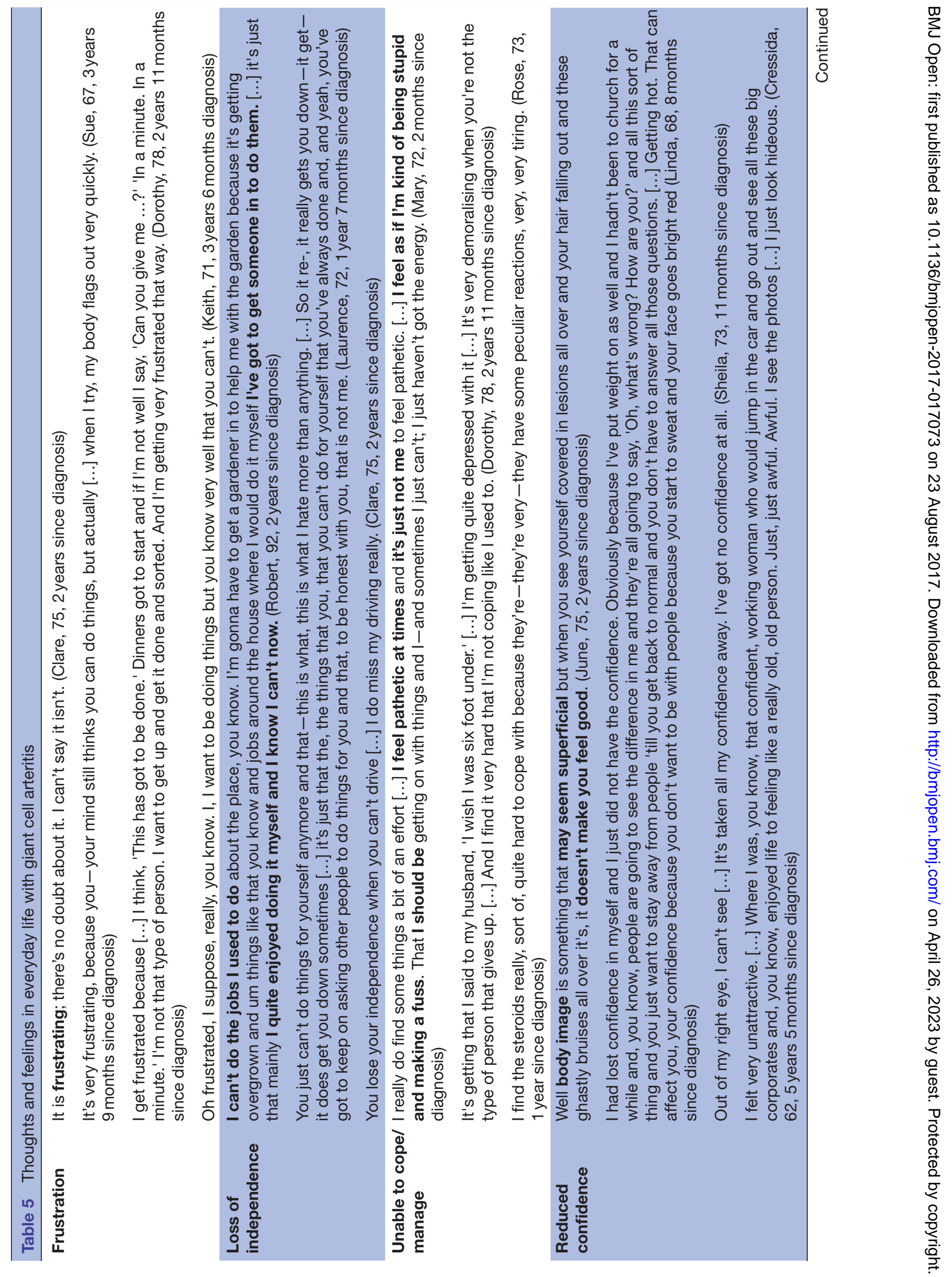




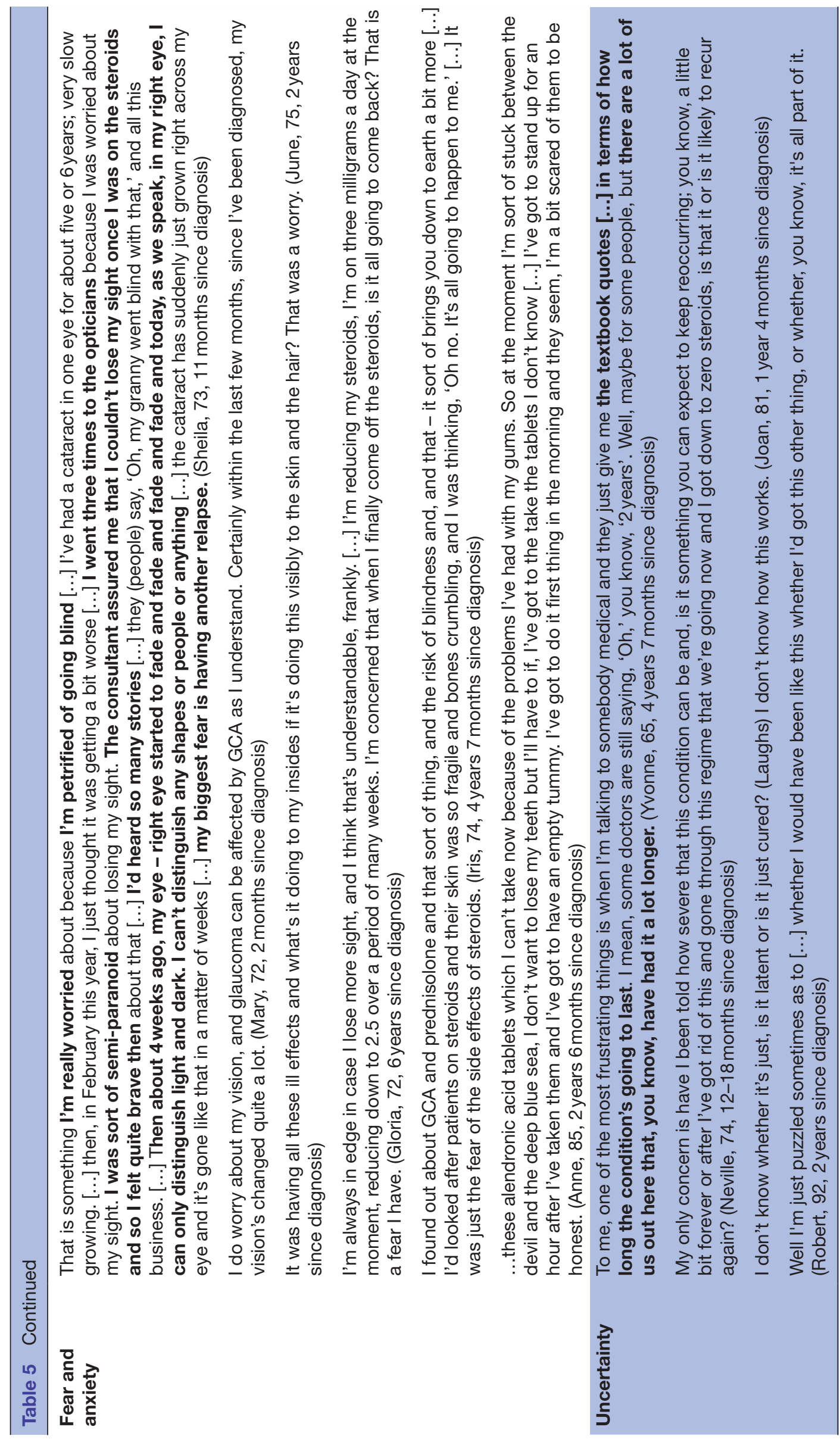


help them maintain independence and retain or restore a sense of normality.

Acknowledgements The authors thank all the respondents who gave their time to be interviewed, and the PMRGCAuk charity for help with recruitment advertising.

Contributors Study design and conception: CDM, JL, JCR, TH and JAP. Data collection: RB. Data analysis and interpretation: JL, RB, JCR, SLM and CDM. Manuscript preparation: JL, RB, JCR, CDM, SLM, JAP and TH.

Funding This paper presents independent research funded by the National Institute for Health Research School for Primary Care Research (NIHR SPCR), Grant Reference Number 294. CDM is funded by the NIHR Collaborations for Leadership in Applied Health Research and Care West Midlands, the NIHR School for Primary Care Research and an NIHR Research Professorship in General Practice (NIHR-RP-201404-026). SLM is funded by an NIHR Clinician Scientist Award. The views expressed are those of the author(s) and not necessarily those of the NHS, the NIHR or the Department of Health.

Competing interests We have read and understood BMJ policy on declaration of interests and declare the following interests: CDM and RB had support from the National Institute for Health Research School for Primary Care Research (NIHR SPCR) for the submitted work. SLM received an honorarium for serving on a Medical Advisory Board for Chugai Roche Pharmaceuticals. All the authors have no other financial relationships with any organisation that might have an interest in the submitted work in the previous 3 years; no other relationships or activities that could appear to have influenced the submitted work.

Patient consent Detail has been removed from these case descriptions to ensure anonymity. The editors and reviewers have seen the detailed information available and are satisfied that the information backs up the case the authors are making.

Ethics approval Keele University's Research Ethics Committee.

Provenance and peer review Not commissioned; externally peer reviewed.

Data sharing statement Keele Research Institute for Primary Care and Health Sciences has established data sharing arrangements to support joint publications and other research collaborations. Applications for access to anonymised data from our research databases are reviewed by the Centre's Data Custodian and Academic Proposal (DCAP) Committee and a decision regarding access to the data is made subject to the ethical approval first provided for the study and to new analysis being proposed. Further information on our data sharing procedures can be found on the Institute's website (http://www.keele.ac.uk/pchs/publications/ datasharingresources/) or by emailing primarycare.datasharing@keele.ac.uk.

Open Access This is an Open Access article distributed in accordance with the terms of the Creative Commons Attribution (CC BY 4.0) license, which permits others to distribute, remix, adapt and build upon this work, for commercial use, provided the original work is properly cited. See: http://creativecommons.org/ licenses/by/4.0/ (c) Article author(s) (or their employer(s) unless otherwise stated in the text of the article) 2017. All rights reserved. No commercial use is permitted unless otherwise expressly granted.

\section{REFERENCES}

1. Smeeth L, Cook C, Hall AJ. Incidence of diagnosed polymyalgia rheumatica and temporal arteritis in the United Kingdom, 1990-2001. Ann Rheum Dis 2006;65:1093-8.

2. Dasgupta B, Borg FA, Hassan N, et al. BSR and BHPR guidelines for the management of giant cell arteritis. Rheumatology 2010;49:1594-7.

3. Proven A, Gabriel SE, Orces C, et al. Glucocorticoid therapy in giant cell arteritis: duration and adverse outcomes. Arthritis Rheum 2003;49:703-8.

4. Hellmann DB, Uhlfelder ML, Stone JH, et al. Domains of healthrelated quality of life important to patients with giant cell arteritis. Arthritis Rheum 2003:49:819-25.

5. Aydin SZ, Direskeneli H, Sreih A, et al. Update on Outcome measure development for Large Vessel Vasculitis: report from OMERACT 12. J Rheumatol 2015;42:2465-9.

6. Borg M, Davidson L. The nature of recovery as lived in everyday experience. J Ment Health 2008;17:129-40.

7. Mason M. Sample size and saturation in $\mathrm{PhD}$ studies using qualitative interviews. Forum Qual Soc Res 2010;11. art 8.

8. Ritchie J, Lewis J, Elam G. Designing and selecting samples. In: Ritchie J, Lewis J, eds. Qualitative research practice: a guide for social science students and researchers. 2003.

9. Strauss A, Corbin J. Basics of Qualitative Research: techniques and procedures for developing Grounded Theory. 1998.

10. Braun V, Clarke V. Using thematic analysis in psychology. Qual Res Psychol 2006;3:77-101.

11. Twohig H, Mitchell C, Mallen C, et al. "I suddenly felt I'd aged": a qualitative study of patient experiences of polymyalgia rheumatica (PMR). Patient Educ Couns 2015;98:645-50.

12. Hall NJ, Rubin GP, Dougall A, et al. The fight for 'health-related normality': a qualitative study of the experiences of individuals living with established inflammatory bowel disease (ibd). J Health Psychol 2005;10:443-55.

13. Brooks HL, Rogers A, Sanders C, et al. Perceptions of recovery and prognosis from long-term conditions: the relevance of hope and imagined futures. Chronic IIIn 2015;11:3-20.

14. Langelaan M, de Boer MR, van Nispen RM, et al. Impact of visual impairment on quality of life: a comparison with quality of life in the general population and with other chronic conditions. Ophthalmic Epidemiol 2007;14:119-26.

15. Aiello PD, Trautmann JC, McPhee TJ, et al. Visual prognosis in giant cell arteritis. Ophthalmology 1993;100:550-5.

16. Salvarani C, Cimino L, Macchioni P, et al. Risk factors for visual loss in an Italian population-based cohort of patients with giant cell arteritis. Arthritis Rheum 2005;53:293-7. 